Centro de Estudios Históricos. Dirección de Investigación, Universidad Bernardo O'Higgins. Santiago, Chile. aProfesor de Historia y Geografía.

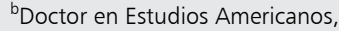
mención Pensamiento y Cultura. 'Doctor en Historia.

Recibido el 25 de enero de 2017, aceptado el 16 agosto de 2017 .

Correspondencia a:

Dr. Germán Morong Centro de Estudios Históricos, Universidad Bernardo O'Higgins. Fábrica, $1990,2^{\circ}$ piso, Santiago, Chile. Teléfono: 224772214 german.morong@ubo.cl

\section{El 'humor' de los indios en el saber médico de los siglos XVI-XVII}

\author{
GERMÁN MORONG R. ${ }^{\mathrm{a}, \mathrm{b}}$, VÍCTOR BRANGIER P. ${ }^{\mathrm{a}, \mathrm{c}}$
}

\section{Indian 'humor' in medical knowledge during the $16^{\text {th }}$ and $17^{\text {th }}$ centuries}

\begin{abstract}
During the first Modern Era $\left(15^{\text {th }}-17^{\text {th }} c\right.$ c.), bodily health and expressions of physiognomy were explained under the doctrine of humors. This doctrine -based on Corpus Hipocraticum-established a close relation between humors (blood, yellow bile, phlegm, and black bile), qualities (dry, moist, warm, and cold) and the elements (water, air, earth, and fire). One of these humors-black bile-, commonly a hallmark of the melancholic temperament, was associated to the complexion and nature of American Indians. This accusation was legitimized by the empirical examination of the physiognomy of a subject that was melancholic, sad and pusillanimous. In this article, we describe, based on the analysis of colonial texts $\left(16^{\text {th }}-17^{\text {th }} c\right.$ c.), how the essential premises of the humor theory were transferred to the New World and in particular and how the Indian complexion was defined through the examination of subjects plagued by black humor and phlegm. With this, we determine the way these individuals-referred as 'Indians'- were inscribed in medical knowledge, during the global spread of the Hippocratic-Galenic postulates.
\end{abstract}

(Rev Med Chile 2017; 145: 920-925)

Key words: Colonialism; Humor; Humoralism; Indians, South American; Physiognomy.

\section{$\mathrm{E}$} n la Europa moderna, la salud corporal y la complexión de un individuo fueron explicadas bajo la llamada doctrina de los humores. Esta fue formulada inicialmente por la medicina griega del siglo VI a. C., ejerciendo una influencia decisiva en el pensamiento europeo hasta principios del siglo XVIII ${ }^{1}$. Durante este periodo, y hasta el Renacimiento, dominó el sistema hipocrático, basado en una correspondencia general entre los humores (sangre, bilis amarilla, flema, bilis negra), las cualidades (seco, húmedo, caliente, frío) y los elementos (agua, aire, tierra, fuego $)^{2}$. Del predominio de unos u otros humores se derivaron, para los hipocráticos, estos diversos temperamentos: sanguíneo, flemático, bilioso y melancólico. Al "Corpus Hippocraticum" se incluyeron, además, los legados de Claudius Galeno (129-200 d. C.) y Aristóteles (384-322 a. C.). Por ello, la salud corporal y su balance derivaban de un precario equilibrio, caóticamente dominado por alguno de los cuatro humores. A su vez, la complexión de un sujeto hacía referencia al "color del cuerpo" que los humores dejaban traslucir. Desde la antigüedad clásica a la Edad Media el tizne de la piel se explicaba, desde una perspectiva médica, mediante la constitución humoral del cuerpo ${ }^{3}$.

Siguiendo este razonamiento, a partir del color del cuerpo-complexio-se pretendió conocer también la calidad moral de ciertos individuos y se aceptó -de acuerdo al corpus galénico- un estricto cuadro de correspondecias entre las condiciones geográficas y las condiciones físicas y psíquicas de los individuos a lo largo del orbe conocido (así, por ejemplo, el color de piel negra era producto del insoportable calor ecuatorial y 
el blanco de zonas boreales y frías). Con todo, la complexión del cuerpo era el resultado de la proporcionalidad de humores y significaba, más allá del orden físico, una moralidad determinaba en estricta coherencia con la tradición fisiognomática "mediante la cual se procuraba captar la bondad o maldad de un sujeto con base a su apariencia física""

Al igual que judíos y negros, los indios americanos se constituyeron -a partir de la colonización ibérica- en objetos de significación a partir del color de su piel y del lugar en que habitaban. A todos ellos se les imputó una condición corporal o una complexio vinculada a la preponderancia del humor melancólico y flemático, que expresó un tipo de moralidad y conducta específica al interior del orden clasificatorio médico de los siglos XV-XVIII. A continuación revisamos sintéticamente, a partir de un corpus documental acotado, que tales asignaciones médicas fueron transferidas a los indios americanos con un alto grado de esencialismo generalizante; bajo el enunciado "son lo primero los indios de cuantas naciones hasta aquíse han descubierto", se homologaron las diferencias socioculturales al interior del paraguas unificador de la "indianidad".

Esta transferencia de saberes utilizada para describirlos-en tanto práctica etnográfica- implicó una serie de analogías y correspondencias estratégicas entre las significaciones y representaciones generalizadas sobre los individuos de complexión melancólica en el Viejo Mundo y las prácticas y comportamientos observados en los indios a lo largo y ancho de las Indias Occdentales, transferencia que hemos analizado en otro trabajo ${ }^{5}$. La complexio, con la cual se representó a los naturales, fue vinculada estratégicamente a su condición psíquica y física, esto es, signar a los indios de melancólicos y flemáticos. A continuación, proponemos describir tales expresiones humorales vinculadas por los conquistadores ibéricos a determinadas conductas morales observadas en los indios, y que justificaron la naturalización de estructuras estamentales de larga duración. Se revisarán las descripciones médicas de Juan de Matienzo (1567), Francisco Cervantes de Salazar (1575), López de Velasco (1574), Gregorio García (1607), Martín de Murúa (1613), Diego Cisneros (1617) y Bernabé Cobo (1653).

\section{El humor melancólico y los saberes médicos, s. XVI-XVII}

El medio intelectual humanista del siglo XVI concordaba en que la melancolía -en tanto descompensación del equilibrio de humoresera sinónimo de una gradual tristeza que iba degenerando en locura. En 1613, el mismo Robert Burton nos advertía que la melancolía "en general se define como un tipo de locura sin fiebre que tiene como compañeros comunes al temor y a la tristeza, sin ninguna razón aparente" ${ }^{\text {. El Corpus }}$ Hippocraticus y el Corpus Doctrinal de Galeno ${ }^{7}$, seguido por los médicos y filósofos modernos, coincidía en que la melancolía no es inherentemente patógena; no es una enfermedad hasta que excede los otros estados de ánimo, expresando así una perturbación del equilibrio del cuerpo y del mundo. La perspectiva aristotélica, desarrollada en los conocidos "Problemas XXX", relacionaba un estado físico perturbado (physis) con otro anímico defectivo (phyche) $)^{9}$.

En su obra "De las enfermedades melancólicas" (1597), el médico francés André Du Laurens ${ }^{10}$ sostenía que la melancolía podía clasificarse en dos tipos: por un lado, si la bilis negra se mezclaba con un flujo de sangre permanente, era la responsable de los más altos ingenios y capacidades intelectuales (argumento que toma de Aristóteles). Por el contrario, otra especie de melancolía, aquella producida por un exceso de bilis negra quemada, fría y seca, incidía en una expresión anímica de sujetos groseros, lentos, tontos, tímidos, temerosos, perezosos y pusilánimes ${ }^{11}$. También miedosos y tristes, sin motivo aparente alguno. Para Aristóteles, esta condición de la expresión anímica podía conducir al suicidio. En 1305, el médico francés Bernard de Gordon en su "Lilium Medicine" había atribuido a los judíos el padecimiento melancólico, al señalar que estos se mostraban ociosos, temerosos y pusilánimes ${ }^{12}$. A su vez, el mismo Du Laurens emparentaba este humor con aquel producido por la preponderancia de la flema. Para él, los sujetos flemáticos solían ser estúpidos, de juicio lento y tenían dormidas todas las potencias nobles del alma, dado que la sustancia de su cerebro era grasa. La falta de "nobleza" y su actitud grosera los volvía inadecuados para ocupar altos cargos. 
El humor de los indios en la historia de la colonización americana - G. Morong et al

\section{La melancolía y la flema en los textos de Indias}

Siguiendo las apreciaciones de Rebecca Earle ${ }^{13}$, los principales tratadistas españoles dedicados a la medicina, y los que vinieron al Nuevo Mundo, aceptaban la tremenda influencia que ejercía el clima y la alimentación en la complexión de los seres humanos. Los españoles adscribían al determinismo climático/alimentario y consideraban a los indios gobernados por el humor negro (preponderancia de la bilis negra) a causa de su vida en climas tropicales, cálidos y húmedos, pero también por una dieta alimentaria saturada de "comidas frías" (raíces, hierbas y peces). Como apunta Earle, esta comida generaba la abundancia de humores fríos que caracterizan el cuerpo del indígena y, consecuentemente, determinaban la naturaleza de su carácter; dócil, tímido y pusilánime.

En 1567, el jurista Juan de Matienzo en su “Gobierno del Perú" $(1567)^{13}$, valiéndose de su experiencia in situ, señalaba que los indios eran " $p u$ silánimes e tímidos, que les viene de ser melancólicos naturalmente, que abundan de cólera adusta fría. Los que este hábito y complesión [sic] tienen (dice Aristóteles) son muy temerosos, floxos e necios; que les viene súbitamente, sin ocasión y causa alguna, muchas congojas y enojo, y si se les pregunta de qué les viene, no sabrán decir porque"'13. Esta asignación médica devenía de la propia complexión del indio "dáse a entender tener esta complesión [sic] por la color del rostro que todos tienen y por su complesión y condición de que se va tratando" (nota). Más adelante insistía en que "los indios naturalmente son fríos, floxos y pusilánimes", concluyendo que son "la gente más triste que yo he visto en mi vida".

Las descripciones sobre el cuerpo y su color implican una relación estratégica entre padecimiento melancólico y carencia de facultades deliberativas y racionales. Para el oidor, los indios carecen de "calor natural" y de ello devienen sus aflicciones psíquicas y su descompensación humoral, hacia un estado de acedia, de temor y pusilanimidad. Como hemos sostenido en una publicación precedente, esta constatación etnográfica permitió sostener la idea de que los indios debían ser tutelados y amparados, ya que el temperamento andino y el desconocimiento de sus propias circunstancias ('no sabrán decir por qué') revelaría un natural estado de embrutecimiento manifiesto en la carencia de facultades políticas para el autogobierno 5 .
Años más tarde, el mercedario Martín de Murúa, en su "Historia General del Perú" (1613), ofrece un cuadro de correspondencias entre el humor y la calidad moral de los sujetos descritos;

"son los indios, por la maior parte, peresosos y que si no es por fuersa, o grandisima necesidad, no echarán mano a darse el trabajo, tristes melancolicos, cobardes, flojos, tibios, viles, mal ynclinados, mentirosos, ingratos a quien les haze bien, de poca memoria y de ninguna firmeza en cosa que tratan..."14.

En su descripción antropológica el fraile, al igual que Matienzo, relaciona a conveniencia el estado anímico y el padecimiento humoral con una serie de antivalores que expresan una ausencia de temple y una incapacidad laboral, obligándolos a ocuparse en oficios "técnicos". Las correspondencias entre la complexio y la respuesta anímica son utilizadas para demostrar que, en la exégesis humoral, los indios eran inferiores a los españoles, dada su natural inclinación. Si se sigue la trayectoria escrita de esta asignación humoral a los indios, tenemos que en 1607, Fray Gregorio García, en su "Origen de los indios del Nuevo Mun$d o$ ", reitera un conjunto de correspondencias entre la falta de calor natural y los vicios devenidos de esta ausencia. Para García:

"Los indios son de coplexión [sic] y temperamento frío y húmedo, [...] Pues como los indios son húmidos de su naturaleza, y no tienen tanto calor natural como es menester para vencer aquella humedad [...] por lo qual son los Indios de poca fuerza $y$ vigor, no muy corpulentos, para poco trabajo; de poco ingenio para letras, afeminados y pusilánimes en lo qual convienen casi todos los Indios de las Indias Occidentales"15.

Esta descripción, al igual que las precedentes, sostiene una relación insistente entre complexión -húmeda y fría, sin calor natural-y calidad moral; débiles, de poco ingenio y afeminados ${ }^{16}$. Con la descripción del médico español Diego Cisneros, asistimos a una argumentación matizada respecto a la relación tipología humoral-expresión anímica en los naturales. En su "Sitio, naturaleza y propiedades de la ciudad de México" (1618), aclara que:

"melancólicos avian de ser los Indios, y mas viendo la facilidad con que aprenden las artes, y oficios 
de qualquier calidad con tan gran perfección, cosas repugnantes a los flemáticos de quien dixo Aristóteles, que para ninguna cosa eran buenos, floxos, pereçosos, y ignorantes [...] son torpes, tardos al movimiento y pereçosos, olvidadiços, insensatos, la color del cuerpo blanca, todo lo qual es repugnante a los Indios, que son ligeros, curiosos, el color tostado tirante y pardisco, hábiles y de ingenio como se ha visto y se vee en las artes que exercitan, para las quales es necesario ingenio y memoria"17.

Realmente interesantes parecen ser los matices con los que se atribuye la calidad de melancólico a los indios. La explicación otorgada por Cisneros para definir la complexio de estos, fractura el sentido de los relatos precedentes al asignar a los naturales ingenio y habilidad para ejecutar tareas y oficios, atribuyendo a la preponderancia de la flema las expresiones anímicas que en los autores anteriores fueron vinculadas al humor melancólico. Interesante es observar que, al parecer, el tipo de melancolía imputada corresponde a un primer tipo, definida en la lógica aristotélica como aquella que es la responsable de las más altas capacidades políticas y artísticas. En tanto, para Matienzo y Murúa, la melancolía que gobierna el espíritu de los naturales se relaciona con aquella, quemada y fría, que los conduce a un estado apático con capacidades intelectuales limitadas.

Estos matices pueden ser advertidos también en las obras de López de Velasco (1574), Cervantes de Salazar (1575) y Bernabé Cobo (1653), autores que describen al indio como flemático. Las expresiones de esta tipología humoral son similares a las que los autores precedentes otorgaron a la complexio melancólica. El primero de ellos, radicado en Nueva España, sostenía que eran "enseñados a servir, flemáticos [...] de flaco ingenio [...] eran también muy holgazanes, viles $y$ apocados [...] y depravados en el entendimiento y uso de la razón", describiendo su cuerpo como débil y flaco "por la relajación del calor y vicio de la tierra"18. Por su parte, el jesuita Bernabé Cobo

Tabla 1. Los Textos coloniales y el Humor de los indios, s. XVI-XVII

\begin{tabular}{|c|c|c|}
\hline Autor y obra & Complexión y humor descrito & Expresiones de ese humor \\
\hline $\begin{array}{l}\text { Juan de Matienzo, } \\
\text { Gobierno } \\
\text { del Perú (1567) }\end{array}$ & $\begin{array}{l}\text { Melancólicos, fríos, padecen cólera } \\
\text { adusta fría }\end{array}$ & $\begin{array}{l}\text { - Temerosos } \\
\text { - Flojos } \\
\text { - Necios } \\
\text { - Pusilánimes } \\
\text { - Vulnerables al suicidio } \\
\text { - Holgazanes } \\
\text { - Sin calor natural }\end{array}$ \\
\hline $\begin{array}{l}\text { Martín de Murúa, } \\
\text { Historia General } \\
\text { del Perú (1613) }\end{array}$ & Melancólicos, fríos & $\begin{array}{l}\text { - Tristes } \\
\text { - Cobardes } \\
\text { - Perezosos, flojos } \\
\text { - Tibios } \\
\text { - Mal inclinados } \\
\text { - Viles }\end{array}$ \\
\hline $\begin{array}{l}\text { Fray Gregorio García, } \\
\text { Origen de los indios } \\
\text { del Nuevo Mundo (1607) }\end{array}$ & Temperamento frío y húmedo & $\begin{array}{l}\text { - Lampiños } \\
\text { - Sin calor natural } \\
\text { - De poca fuerza y vigor } \\
\text { - No corpulentos } \\
\text { - De poco ingenio } \\
\text { - Pusilánimes } \\
\text { - Afeminados }\end{array}$ \\
\hline $\begin{array}{l}\text { Bernabé Cobo, Historia } \\
\text { del Nuevo Mundo (1653) }\end{array}$ & Flemáticos y Sanguíneos & $\begin{array}{l}\text { - No corpulentos } \\
\text { - De poca fuerza y capacidad para el trabajo } \\
\text { - De buena salud corporal }\end{array}$ \\
\hline $\begin{array}{l}\text { Diego Cisneros, Sitio, } \\
\text { naturaleza y propiedades de la } \\
\text { ciudad de México (1618) }\end{array}$ & Melancólicos & $\begin{array}{l}\text { - Buenos para las artes y oficios mecánicos } \\
\text { - Hábiles y de ingenio } \\
\text { - Ligeros y curiosos }\end{array}$ \\
\hline
\end{tabular}

Fuente: Elaboración propia a partir de los textos analizados. 
en 1653 , atribuía a estos la misma "inclinación natural” derivada del humor flemático, reiterando una relación estratégica entre complexión y capacidades físicas:

"son todos naturalmente flemáticos de complexión; y como la flema natural hace blanda y húmeda la sustancia de los miembros del cuerpo tienen muy blandas y delicadas carnes y así, se cansan presto $y$ no son para tanto trabajo como los hombres de Europa"19.

Cobo impone en su descripción un orden clasificatorio que permite legitimar la diferencia antropológica (indio/europeo) sobre la base de la autoridad epistemológica que impuso la doctrina de los humores. Esta verdadera carencia de vigor, fuerza física y una acusada falta de voluntad y decisión son descritas por el coterráneo de López de Velasco, el cronista Francisco Cervantes de Salazar, el cual refería a los naturales de México como "pusilánimes, amigos de estarse ociosos, sin hablar los unos con los otros, la causa es ser muy flemáticos"20. Las conclusiones pragmáticas del cronista era sostener que esta condición permitía ocupar a los indios solo en "oficios mecánicos".

\section{A modo de conclusión}

Las descripciones precedentes implican la consideración de dos puntos fundamentales. En primer lugar, las diferencias que presentan los autores citados respecto a la categoría humoral que se les imputa a los indios, son indicativas, o prueba, que en los siglos XVI y XVII la complexión de estos era relatada con matices respecto a la relación complexión-respuesta anímica. Para Matienzo, Murúa, García y Cisneros, los indios hundían su estado anímico en el humor melancólico y, por ello, expresaban conductas caracterizadas por el temor, la angustia y la pusilanimidad. Para López de Velasco, Cobo y Cervantes de Salazar, estos eran flemáticos, diariamente groseros y estúpidos, a la vez que ociosos y pusilánimes. Tanto la melancolía como la flema sirvieron para hacer a los indios más legibles desde el saber médico, constatando empíricamente las premisas humorales sobre el cuerpo en el Nuevo Mundo. Esta identificación, amparada en un corpus de saber específico, sirvió estratégicamente para gobernar y sujetar a los indios bajo la premisa evidente de su inferioridad inherente. Los textos en comento vinculan la preponderancia de la melancolía y la flema a conductas y prácticas sociales abominables, en estricta oposición a la ortodoxia cristiana. En segundo lugar, estas constataciones permitieron justificar su tutela e hispanización progresiva, a la vez que naturalizar una condición servil en aquellos, producto de su falta de ingenio y sofisticación intelectual. Si se establece un cuadro de correspondencias entre el tipo de humor y las calidades morales de los indígenas, tenemos que:

Esta condición -asignada arbitrariamente a los indígenas- operó a partir de una serie de transferencias epistemológicas, cuyo objetivo fue presentar una imagen de estos con claras referencias al corpus médico moderno (s. XV-XVIII), inscribiendo el cuerpo humano en una red discursiva hegemónica, cuyas consecuencias, siempre en el ámbito del colonialismo, inciden en la construcción de una identidad generalizante para los pueblos amerindios y afroamericanos con una fuerte carga estereotípica.

\section{Referencias}

1. Ortega F. Humor negro e historia. Rev Historia y Grafía 2006; 27: 205.

2. Starobinski, J. L’ encre de la mélancolie. París: Seuil; 2012.

3. Hering, M. Saberes médicos-Saberes teológicos: de mujeres y hombres anómalos. En: Hering, M, editor, Cuerpos Anómalos. Bogota: Editorial de la Universidad Nacional; 2008.

4. Hering M. Color, pureza, raza: La calidad de los sujetos coloniales. En: Bonilla, H, editor, La cuestión colonial. Bogotá: Universidad Católica de Bogotá; 2011.

5. Morong G. Saberes hegemónicos y proyecto de dominio colonial: Los indios en la obra Gobierno del Perú de Juan de Matienzo (1567). Rev. Fronteras de la Historia 2013; 18 (2): 77-103.

6. Burton, R. Anatomía de la melancolía. Buenos Aires: Espasa-Calpe; [1621] 1947.

7. Klibansky R, Panofsky E, Fritz S. (eds.). Saturno y la Melancolía. Madrid: Alianza Editorial, 1991.

8. Aristóteles. Problemas en torno a reflexión, mente y sabiduría. Traducción de Santiago González Escudero. Psicothema 1990; No 3: 245-58.

9. Jalón M. Ciencias en lenta evolución, hacia 1600: Du Laurens y Guibelet, En: M. Jalón (ed.), De las enfermedades melancólicas. Del humor melancólico. Madrid: Asociación Española de Neuropsiquiatría; 2011. 
10. Morong G. De la natural inclinación y condición de los indios. El oidor Matienzo y su proyecto de gobernabilidad para el Perú virreinal, 1567. Rev Diálogo Andino 2013; 42: 25.

11. Gordonio B. Lilio de Medicina. Madrid: Antonio González de Reyes; [1305] 1697, Fol. 153-6.

12. Earle R. The Body of the Conquistador: Food, Race and the Colonial Experience in Spanish America, 1492-1700. Cambridge: Cambridge University; 2012.

13. de Matienzo J. Gobierno del Perú. París-Lima: Institut Francais D’ Études Andines; [1567] 1967.

14. de Murúa M. Historia General del Perú. Madrid: Instituto Gonzalo Fernández de Oviedo; [1613] 1964.

15. García G. Origen de los indios de el Nuevo Mundo, e indias occidentales. Valencia: Imprenta Pedro Mey; [1607].

16. Morong G. Dispositivos de sujeción colonial. El uso de la condición melancólica en dos texto de indias (1567/1616). Rev de Humanidades 2014; 30: 167-13.

17. Cisneros D. Sitio, naturaleza y propiedades de la ciudad de México. Aguas y Vientos a que esta sujeta; y Tiempos del Año. Necesidad de su conocimiento para el exercicio de la Medicina, su incertidumbre y difficultad sin el de la Astrologia assi para la curacion como para los prognosticos. México: Casa del Bachiller Juan Blanco de Alcaçar; [1618]. p. 112v-112r.

18. López de Velasco J. Geografía y descripción universal de las Indias. Madrid: Establecimiento tipográfico de Fortanet; [1574] 1894. p. 30.

19. Cobo B. Historia del Nuevo Mundo. Madrid: Ediciones Atlas; [1653] 1964, T. II, p. 15.

20. Cervantes de Salazar F. Crónica de la Nueva España. Madrid: Tipología de la Revista de Archivos; [1575] 1914. p. 30 . 